\title{
Perineal Pain, CTCAE 5.0
}

National Cancer Institute

\section{Source}

National Cancer Institute. Perineal Pain, CT CAE 5.0. NCI Thesaurus. Code C146681.

A disorder characterized by a sensation of marked discomfort in the area between the genital organs and the anus. 